\title{
Caspase-mediated cleavage of C53/LZAP protein causes abnormal microtubule bundling and rupture of the nuclear envelope
}

Jianchun $\mathrm{Wu}^{1, *}$, Hai Jiang ${ }^{2, *}$, Shouqing Luo ${ }^{3}$, Mingsheng Zhang, ${ }^{4,5}$, Yinghua Zhang ${ }^{4}$, Fei Sun ${ }^{6}$, Shuang Huang ${ }^{4}$, Honglin $\mathrm{Li}^{4}$

${ }^{I}$ Cancer Center, University of Illinois at Chicago, Chicago, IL 60612, USA; ${ }^{2}$ Shanghai Institute of Biochemistry and Cell Biology, Shanghai 200031, China; ${ }^{3}$ Cambridge Institute for Medical Research, Department of Medical Genetics, University of Cambridge, Cambridge CB2 OXY, UK; ${ }^{4}$ Department of Biochemistry and Molecular Biology, Cancer Center, Georgia Health Sciences University, Augusta, GA 30912, USA; ${ }^{5}$ Department of Oncology, Tongji Hospital, Tongji Medical College, Huazhong University of Science \& Technology, Wuhan 430030, China $;{ }^{6}$ Department of Physiology, Wayne State University, Detroit, MI 48202, USA

Apoptotic nucleus undergoes distinct morphological and biochemical changes including nuclear shrinkage, chromatin condensation and DNA fragmentation, which are attributed to caspase-mediated cleavage of several nuclear substrates such as lamins. As most of active caspases reside in the cytoplasm, disruption of the nuclear-cytoplasmic barrier is essential for caspases to reach their nuclear targets. The prevailing proposed mechanism is that the increase in the permeability of nuclear pores induced by caspases allows the caspases and other apoptotic factors to diffuse into the nucleus, thereby resulting in the nuclear destruction. Here, we report a novel observation that physical rupture of the nuclear envelope (NE) occurs in the early stage of apoptosis. We found that the NE rupture was caused by caspase-mediated cleavage of C53/LZAP, a protein that has been implicated in various signaling pathways, including NF- $\kappa \mathrm{B}$ signaling and DNA damage response, as well as tumorigenesis and metastasis. We also demonstrated that C53/LZAP bound indirectly to the microtubule (MT), and expression of the C53/LZAP cleavage product caused abnormal MT bundling and NE rupture. Taken together, our findings suggest a novel role of C53/LZAP in the regulation of MT dynamics and NE structure during apoptotic cell death. Our study may provide an additional mechanism for disruption of the nuclear-cytoplasmic barrier during apoptosis.

Keywords: C53/LZAP; caspase; nuclear envelope; microtubule; apoptosis

Cell Research (2013) 23:691-704. doi:10.1038/cr.2013.36; published online 12 March 2013

\section{Introduction}

One of the hallmarks of apoptosis is the distinct change of apoptotic nucleus, including nuclear condensation and DNA fragmentation. These changes are attributed to caspase-mediated cleavage of nuclear substrates such as lamins and nuclear pore components $[1,2]$. As most of the active caspases are primarily cytoplasmic,

*These two authors contributed equally to this work.

Correspondence: Honglin $\mathrm{Li}$

Tel: +1-706-721-6143; Fax: +1-706-721-6608

E-mail: hli@gru.edu

Received 23 July 2012; revised 8 October 2012; accepted 10 December 2012; published online 12 March 2013 the question remains as to how cytoplasmic caspases reach their nuclear targets. One prevailing model is that caspase-9-mediated cleavage of target proteins increases the permeability of nuclear pores during apoptosis, which allows cytoplasmic caspases to diffuse into the nucleus [1]. However, the target(s) of caspase-9 remains unknown, and how cleavage of those targets affects the permeability of nuclear pores also remains elusive.

Cdk5 activator-binding protein C53 (also known as Cdk5rap3 and LZAP) was originally identified as a binding protein of Cdk5 activator and ARF protein [3, 4]. Recent studies suggest that it functions in various signaling pathways, ranging from transcriptional regulation to cell cycle progression [5-7]. Genetic study in zebrafish demonstrates that C53/LZAP is essential for normal 
animal development [8]. Our previous studies have demonstrated its involvement in modulating cell cycle checkpoint by negatively regulating checkpoint kinases $[6,7]$. Moreover, it plays an important role in tumorigenesis and metastasis. By direct binding to Rel A subunit and suppressing $\mathrm{NF}-\mathrm{\kappa B}$ transcriptional activity, $\mathrm{C} 53 /$ LZAP functions as a putative tumor suppressor in head and neck cancers [5]. Recently, its involvement in hepatocellular carcinomas (HCC) and colorectal cancers was also reported. Mak et al. [9] reported that C53/LZAP was widely overexpressed in $\mathrm{HCC}$ and that overexpression of C53/LZAP promoted HCC metastasis through PAK4 activation, whereas the study conducted by Zhao et al. [10] suggested that C53/LZAP could be a tumor suppressor in HCC tumorigenesis. In colorectal cancers, expression of an isoform of C53/LZAP was positively correlated with the grade and depth of invasion of adenocarcinoma of the colon [11]. Clearly, more clinical studies are needed to establish its role in disease pathogenesis, especially in cancer and its metastasis.

C53/LZAP is a highly conserved protein, but has no well-defined functional domains except a putative leucine zipper motif. In correlation with its potential diverse functions, C53/LZAP was found in multi-subcellular compartments, including cytosol, nucleus, nucleolus and centrosomes $[5,7,12,13]$. Not surprisingly, it was reported to interact with a wide range of proteins, including p35 [3], Rel A [5], Chk1/2 [7], PAK4 [9], ARF [4], p38 MAPK [14], Ufl1 (also known as RCAD, NLBP and Maxer) [12, 15-17] and $\gamma$-tubulin [13]. Yet the underlying biochemical nature of these protein-protein interactions remains largely unclear.

We report here that C53/LZAP is a novel caspase substrate. Caspase-mediated cleavage of C53/LZAP generates several fragments, and one of its carboxy (C)-terminal fragments (C53/LZAP-C3) is capable of inducing irregular nuclear morphology. This nuclear irregularity is mainly caused by rupture of the nuclear envelope (NE), which results from excessive microtubule (MT) bundling induced by C53/LZAP-C3. This study may provide an additional mechanism for disruption of the nuclear-cytoplasmic barrier during apoptosis. Furthermore, our study also sheds light on the possible involvement of C53/ LZAP in the regulation of MT dynamics, and will facilitate our understanding of its role in animal development and human diseases such as cancer.

\section{Results}

\section{C53/LZAP is a novel caspase substrate}

In an attempt o identify novel caspase substrates, we performed a large-scale screening using a strategy of in vitro expression cloning [18]. About $1800 \mathrm{cDNA}$ small pools (100 clones per pool) were screened, and the individual cDNA clones encoding candidate substrates were isolated. Among them, C53/LZAP was isolated. The human C53/LZAP protein has 506 amino acid residues with predicted molecular weight of 57 kilo Dalton $(\mathrm{kD})$, and migrates as a $66 \mathrm{kD}$ band on SDS-PAGE (Figure 1A). Full-length C53/LZAP protein was cleaved in vitro by caspase- 3 into 4 fragments $(32 \mathrm{kD}, 31 \mathrm{kD}, 29 \mathrm{kD}$ and $25 \mathrm{kD}$ ) and partially cleaved into $38 \mathrm{kD}$ and $26 \mathrm{kD}$ fragments by caspase- 8 , but was resistant to caspase- 2 and Granzyme B. The activities of caspase- 2 and Granzyme B were confirmed by in vitro cleavage assay using caspase-2 precursor and BID as specific substrates, respectively (Supplementary information, Figure S1). We also tested the C-terminal Flag-tagged C53/LZAP protein expressed in HeLa cells. After incubation with caspase-3 in vitro, Flag antibody readily detected three Flag-tagged cleavage products $(31 \mathrm{kD}, 29 \mathrm{kD}$ and $25 \mathrm{kD})$ (Figure 1B). Interestingly, C53/LZAP was also efficiently cleaved into two fragments $(35 \mathrm{kD}$ and $22 \mathrm{kD})$ by mcalpain (Figure 1A), indicating that C53/LZAP activity is regulated by multiple proteolytic processes.

We further investigated whether endogenous C53/ LZAP was cleaved during apoptosis. As shown in Figure $1 \mathrm{C}$, endogenous C53/LZAP was processed to multiple fragments when HeLa cells underwent apoptosis induced by the treatment of tumor necrosis factor alpha (TNF $\alpha)$ and cycloheximide (CHX) (Figure 1C). It was also cleaved in apoptosis induced by DNA topoisomerase II inhibitor etoposide, a potent chemotherapeutic agent (Figure 1D). Interestingly, the cleavage patterns under these two conditions appeared different. In TNF $\alpha$-induced apoptosis, C53/LZAP cleavage generated multiple cleavage products including major $31 \mathrm{kD}$, $29 \mathrm{kD}$ and $25 \mathrm{kD}$ fragments (designated as $\mathrm{C} 1, \mathrm{C} 2$ and $\mathrm{C} 3$, respectively) and a minor $26 \mathrm{kD}$ band (indicated by an arrow, a possible modified form of $25 \mathrm{kD}$ fragment) (Figure 1C). With increasing cell death, the $31 \mathrm{kD} \mathrm{C1}$ fragment decreased, whereas the $25 \mathrm{kD} \mathrm{C} 3$ fragment accumulated, indicating that the $31 \mathrm{kD} \mathrm{C} 1$ fragment was further processed to smaller fragments. In contrast, the $25 \mathrm{kD} \mathrm{C} 3$ fragment was the major C53/LZAP cleavage product in etoposide-induced apoptosis (Figure 1D). The kinetics of C53/LZAP cleavage was comparable with the activation of caspases (Figure 1C and 1D), suggesting that C53/LZAP cleavage is a relatively early event during apoptosis. To confirm whether C53/LZAP was cleaved by caspases, we tested if zVAD-fmk, a pancaspase inhibitor, could prevent endogenous C53/LZAP cleavage. As shown in Figure 1E, zVAD-fmk $(100 \mu \mathrm{M})$ effectively blocked C53/LZAP cleavage in apoptosis in- 
A
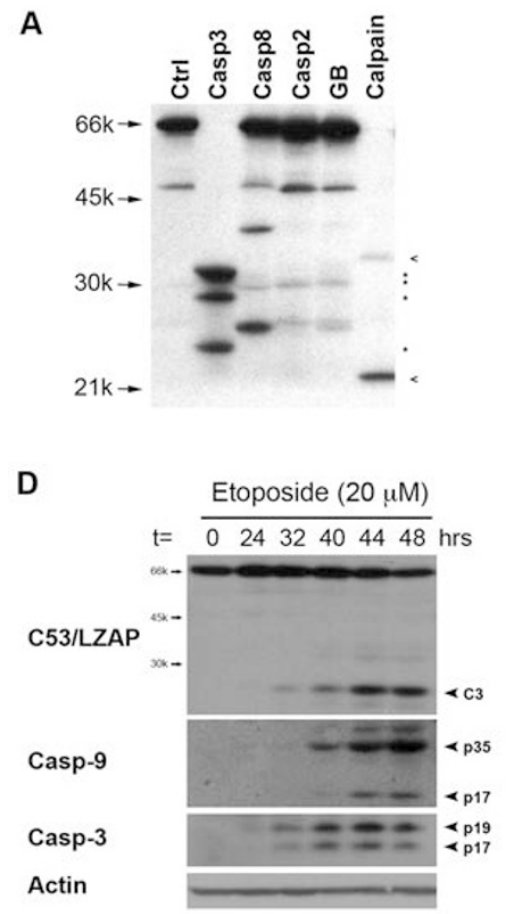

B

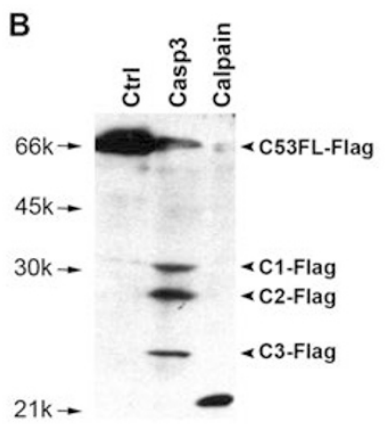

E
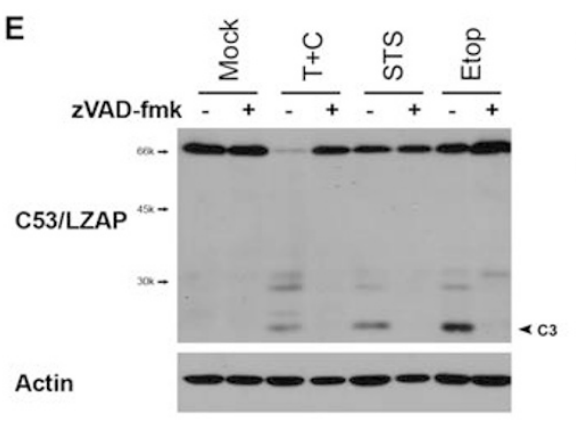

C

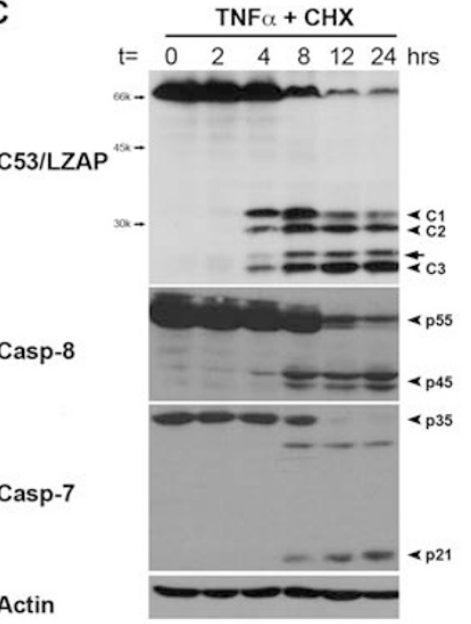

Figure 1 C53/LZAP is a novel caspase substrate. (A) In vitro cleavage of C53/LZAP. ${ }^{35}$ S-labeled C53/LZAP was incubated with control bacterial lysate (Ctrl), caspase-3, caspase-8, caspase-2, Granzyme B (GB) and m-calpain at $30{ }^{\circ} \mathrm{C}$ for 1 h. 5 $\mathrm{mM} \mathrm{Ca}{ }^{2+}$ was present in calpain cleavage. Caspase-3 cleavage products were indicated by stars, while calpain cleavage products were marked by <. (B) In vitro cleavage of C-terminal Flag-tagged C53/LZAP expressed in HeLa cells. Cell lysate containing C53/LZAP-Flag protein was incubated with active caspase-3 or m-calpain. Cleavage of C53/LZAP was detected by immunoblotting with Flag antibody. (C) Endogenous C53/LZAP was cleaved in TNF $\alpha$-induced apoptosis. HeLa cells were treated with TNF $\alpha(10 \mathrm{ng} / \mathrm{ml})$ and $\mathrm{CHX}(10 \mu \mathrm{g} / \mathrm{ml})$ for various periods of time as indicated. The cell lysates were subjected to immunoblotting with various antibodies (C53/LZAP, caspase-7 and -8, actin). C53/LZAP cleavage fragments were marked by arrowheads, while a possible C3-modified form was indicated by an arrow. (D) C53/LZAP was cleaved in etoposide-induced apoptosis. HeLa cells were treated with etoposide (Etop, $20 \mu \mathrm{M}$ ) for various periods of time as indicated. $(E)$ The cleavage of endogenous C53/LZAP was inhibited by pan-caspase inhibitor ZVAD-fmk. HeLa cells were treated with TNF $\alpha(10 \mathrm{ng} / \mathrm{ml})$ plus $\mathrm{CHX}(10 \mu \mathrm{g} / \mathrm{ml})$ for $16 \mathrm{~h}$, staurosporine (STS, $1 \mu \mathrm{M})$ for $16 \mathrm{~h}$ and etoposide $(20 \mu \mathrm{M})$ for $48 \mathrm{~h}$ in the absence or presence of zVAD-fmk $(100 \mu \mathrm{M})$.

duced by multiple stimuli. Taken together, these results demonstrated that endogenous C53/LZAP was indeed cleaved by caspases in both extrinsic and intrinsic apoptotic pathways.

\section{C53/LZAP was sequentially processed at multiple cas- pase-cleavage sites}

Next, we attempted to map the caspase-cleavage sites using site-specific mutagenesis. Based on the size of the cleavage fragments, we speculated that possible cleavage sites were around the middle of C53/LZAP protein. Caspases cleave their target substrates after specific aspartic acid residues, whereas the specificity is determined by upstream 3 or 4 amino acid sequences. C53/LZAP was cleaved by caspase- 3 efficiently (Figure $2 \mathrm{~A}$ and 2D). There are at least 5 potential caspase-3-cleavage sites in the middle portion of C53/LZAP. As shown in Figure
2B, triple mutations at residues D268/D282/D311 to glutamate completely blocked multiple caspase-3 cleavage events, suggesting that these three sites are potential caspase-cleavage sites. Moreover, Flag-tagged C53/LZAP with triple mutations (C53/LZAP-3E) was not cleaved in TNF $\alpha$-induced apoptosis (Figure 2C). The kinetics of in vitro cleavage of full-length C53/LZAP by caspase-3 revealed that C53/LZAP was cleaved in a sequential manner (Figure 2A and 2D). The first cleavage occurred at D268 followed by the cleavages at D282 and D331, generating an N-terminal fragment (C53/LZAP-N, $32 \mathrm{kD}$ ) and three C-terminal fragments (C53/LZAP-C1, -C2 and -C3) (Figure 2D). The sequential cleavage model was further supported by the observation that C53/LZAP-C1 was cleaved by caspase- 3 to generate C53/LZAP-C2 and -C3 (Figure 2D). By using peptide-specific antibodies, we also detected the presence of both $\mathrm{N}$ - and $\mathrm{C}$-terminal 

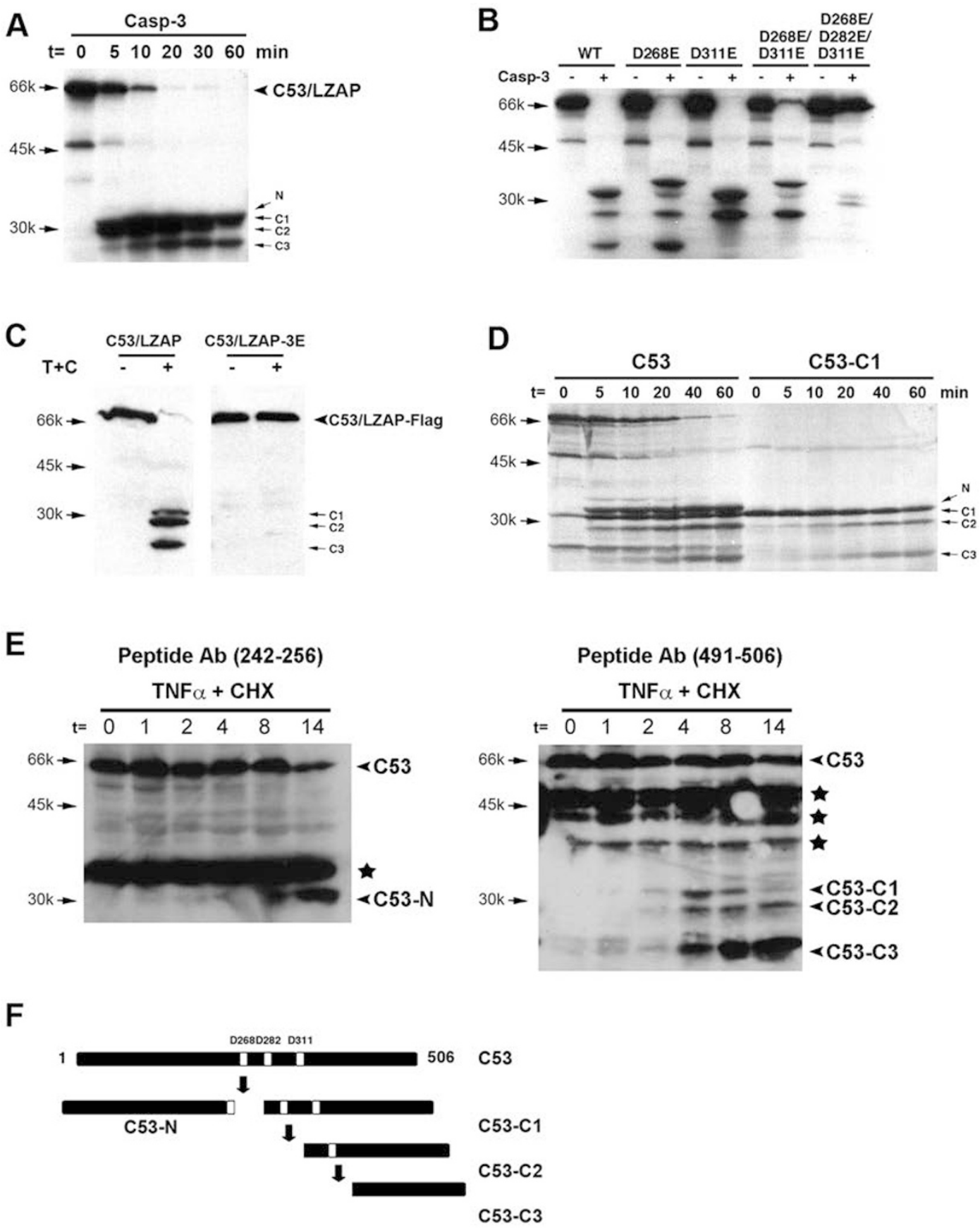

Figure 2 Sequential cleavage of C53/LZAP by caspase-3. (A) Kinetics of caspase-3 cleavage of C53/LZAP in vitro. ${ }^{35}$ Slabeled C53/LZAP was incubated with caspase-3 for various periods of time as indicated, and the cleavage products were analyzed by SDS-PAGE and autoradiography. (B) Determination of caspase-3-cleavage sites by site-specific mutagenesis. Specific aspartic acid residues (D268, D282 and D311) were mutated to glutamate. ${ }^{35}$ S-labeled wild-type C53/LZAP and its mutants were incubated with caspase-3, and the cleavage products were analyzed by SDS-PAGE and autoradiography. (C) C53/LZAP mutant with triple mutations (C53/LZAP-3E) was not cleaved in TNF $\alpha$-induced apoptosis. Wild-type and mutant C53/LZAP-Flag constructs were transfected into HeLa cells that were subsequently treated with TNF $\alpha$ (10 ng/ml) plus CHX (10 $\mu \mathrm{g} / \mathrm{ml}$ ) for $16 \mathrm{~h}$. Cleavage of C53/LZAP-Flag was evaluated by immunoblotting with Flag antibody. (D) Time course of in vitro cleavage of C53/LZAP and C53/LZAP-C1. ${ }^{35}$ S-labeled C53/LZAP and C53/LZAP-C1 (residues 269-506) were incubated with caspase- 3 at $30^{\circ} \mathrm{C}$ for various periods of time as indicated. Identities of the cleavage products were indicated. (E) Immunoblotting of endogenous cleavage products of C53/LZAP using peptide-specific antibodies. Non-specific bands were marked by stars. (F) Sequential cleavage model of C53/LZAP and the constructs that were used in this study. 
fragments in dying cells (Figure 2E). The C53/LZAP cleavage pattern was summarized in Figure 2F.

Expression of C53/LZAP cleavage product, C3, resulted in nuclear irregularity

To investigate the functional significance of C53/ LZAP cleavage during apoptosis, we examined the impact of expression of C53/LZAP cleavage products on subcellular events. The constructs expressing C53/LZAP, C53/LZAP-N or C53/LZAP-C3 were co-transfected into HeLa cells along with H2B-GFP, a live marker for genomic DNA. Expression level of various C53/LZAP constructs was comparable [7]. Intriguingly, the cells expressing C53/LZAP-C3 displayed irregular nuclear morphology with branches and rough edges, whereas the overall cellular shape remained normal (Figure 3A). Around $50 \%$ of $\mathrm{C} 3$-exrepssing cells displayed nuclear irregularity (Figure 3C and 3D). In comparison, expression of full-length or cleavage products $\mathrm{C} 53-\mathrm{N},-\mathrm{C} 1$ and $-\mathrm{C} 2$, had a modest effect on nuclear morphology (Figure $3 \mathrm{~A}$ and 3D). For example, both full-length C53/LZAP and C53/LZAP-N induced nuclear irregularity in less than $10 \%$ of cells, and the irregularity was less severe than the one induced by C53/LZAP-C3 (Figure 3A and 3D). Apparently, the nuclear irregularity induced by $\mathrm{C} 53 /$ LZAP-C3 did not resemble the one induced by defective mitosis, such as micro-, macro- and multi-nucleation. To better understand this novel form of nuclear irregularity, we took advantage of time-lapse microscopy. As shown in Figure 3B, formation of irregular nuclei in C3expressing cells occurred in a relatively short time-frame (one to a few hours) without a cell division, suggesting that the effect of $\mathrm{C} 3$ is unlikely due to defective mitosis. We also tested the effect of two DNA synthesis inhibitors on $\mathrm{C} 3$-induced nuclear irregularity. Both thymidine (2 $\mathrm{mM})$ and hydroxyurea (4 $\mathrm{mM})$ effectively inhibit DNA synthesis and arrest HeLa cells in G1/S phases [7] (Supplementary information, Figure S2). However, neither reagent exerted a significant effect on nuclear irregularity in $\mathrm{C} 3$-expressing cells (Figures $3 \mathrm{C}$ and $5 \mathrm{~A}$ ). These results suggest that the nuclear irregularity induced by C53/LZAP-C3 is independent of cell cycle progression.

C53/LZAP-C3 expression caused NE rupture, an event that occurs in the early stage of apoptosis

To understand the cause of nuclear irregularity induced by C53/LZAP-C3, we examined the integrity of NE. Normal HeLa cells displayed intact NE as indicated by fluorescence staining of lamin B1 (Figure 4A). In contrast, the lamin B staining of C53/LZAP-C3-expressing cells with irregular nuclei were discontinuous and disrupted (Figure 4A). Genomic DNA always "leaked" out at the sites where the lamin B staining was disrupted (Figure 4A). Expression of C53/LZAP and its derivatives did not alter the protein level of lamins (data not shown). Therefore, it is likely that C53/LZAP-C3 may disrupt the physical structure of NE rather than cause loss of individual lamins. This conclusion was strongly supported by the result of electron microscopy. Either the entire or part of NE broke down in C53/LZAP-C3-expressing cells (Figure 4B). Therefore, C53/LZAP-C3 expression caused rupture of NE, which in turn led to the "leaking" of DNA from the nucleus and nuclear irregularity.

It is well known that the integrity of NE is compromised during apoptosis, yet physical rupture of NE has not been reported. To investigate whether the similar event of NE rupture induced by C53/LZAP-C3 also occurs during apoptosis, we examined the NE integrity of HeLa cells undergoing apoptosis. As shown in Figure 4C and $4 \mathrm{D}$, the NE rupture indeed occurred within $2 \mathrm{~h}$ post treatment in HeLa cells treated with TNF $\alpha$ and CHX, and the cells with ruptured NE showed no sign of DNA condensation or detachment from the culture plate (Figure 4C). Similar phenomenon was also observed in U2OS cells treated with either $\mathrm{TNF} \alpha$ and $\mathrm{CHX}$ or the DNAdamaging agent doxorubicin (Supplementary information, Figure S3). This novel observation demonstrated that rupture of NE is an early physiological event during apoptosis. Furthermore, we examined the NE rupture in C53/LZAP-knockdown cells. Interestingly, C53/LZAP knockdown led to decreased NE rupture (Figure 4E). The remaining question is whether C53/LZAP cleavage is responsible for the NE rupture in TNF $\alpha$-induced apoptosis. To address this question, we used a lentiviral vector to reintroduce either wild-type C53/LZAP or cleavagedeficient C53/LZAP-3E mutant that is resistant to C53/ LZAP shRNA back into C53/LZAP knockdown cells along with a red fluorescence protein (RFP) marker (Figure 4F), and then examined the NE rupture in those cells. Expression of C53/LZAP in control cells slightly promoted the NE rupture induced by TNF $\alpha$ treatment (Figure 4G). Importantly, reintroduction of wild-type C53/ LZAP into C53/LZAP-knockdown cells fully restored TNF $\alpha$-induced NE rupture, while C53/LZAP-3E mutant was less efficient compared to its wild-type counterpart. These results strongly suggest that caspase-mediated cleavage of C53/LZAP plays a critical role in the NE rupture during $\mathrm{TNF} \alpha$-induced apoptosis of HeLa cells.

\section{C53/LZAP-C3 expression led to abnormal MT bundling.}

As C3-induced nuclear irregularity was not caused by defective cell cycle progression, we speculated that it may be a consequence of abnormal cytoskeletal activity. To test this hypothesis, we examined the effect 
A
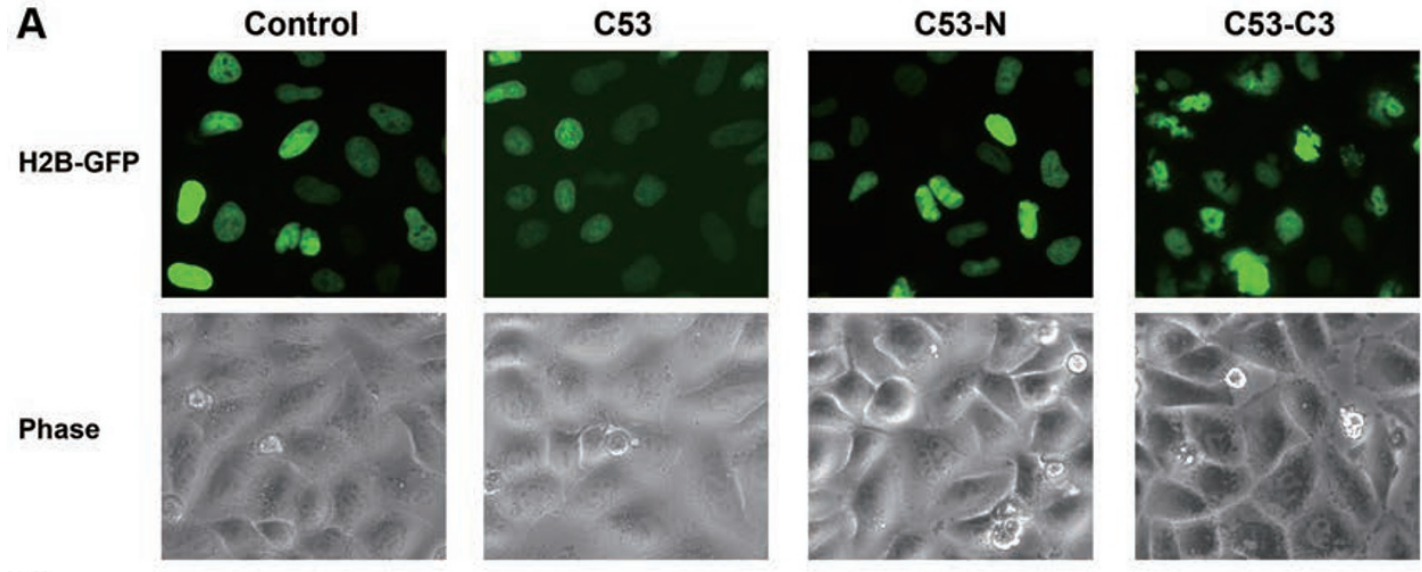

B

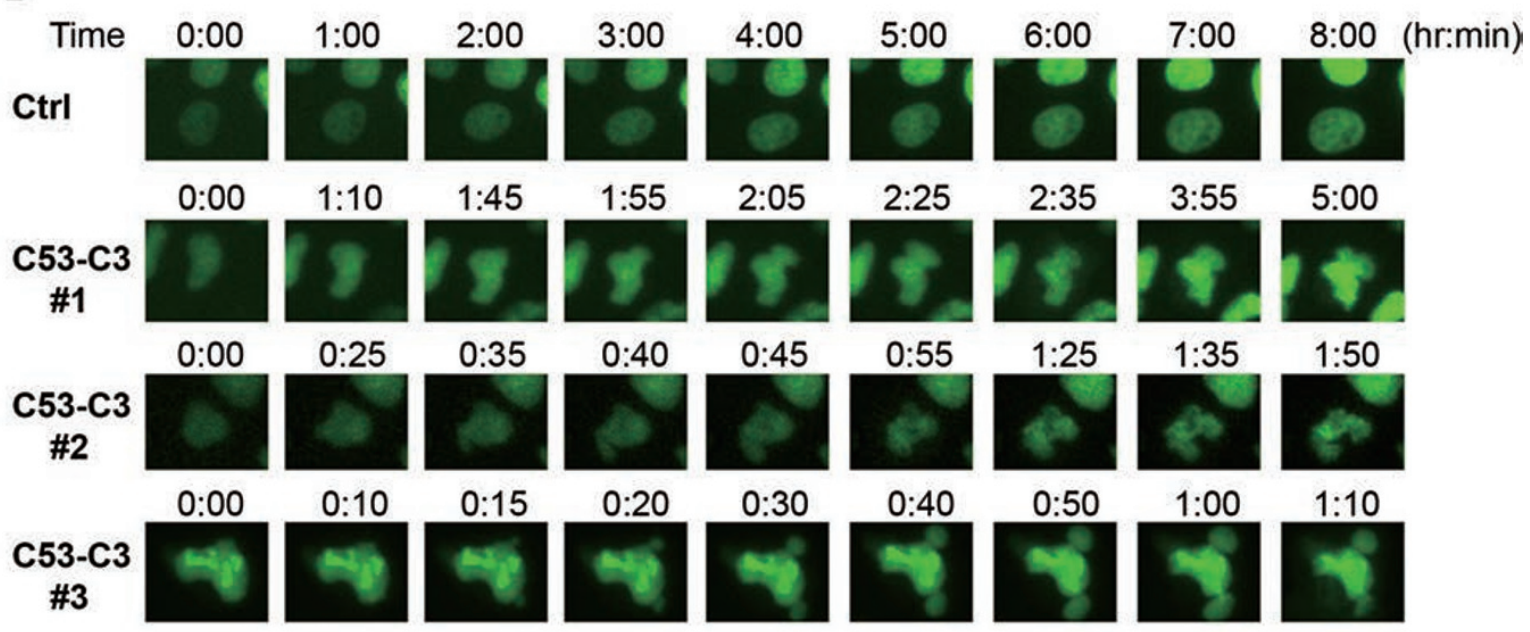

C

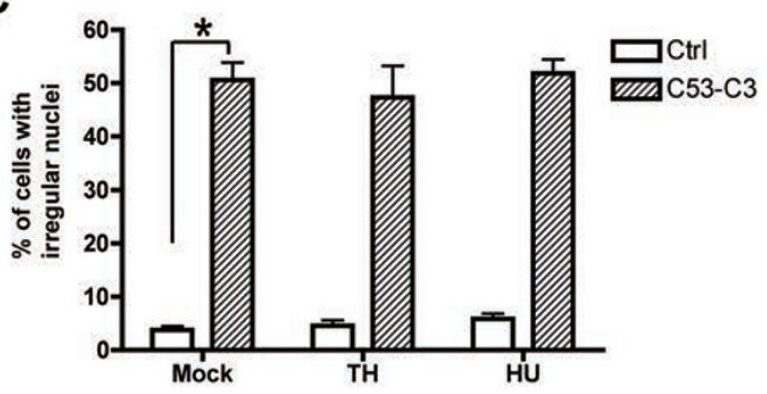

D

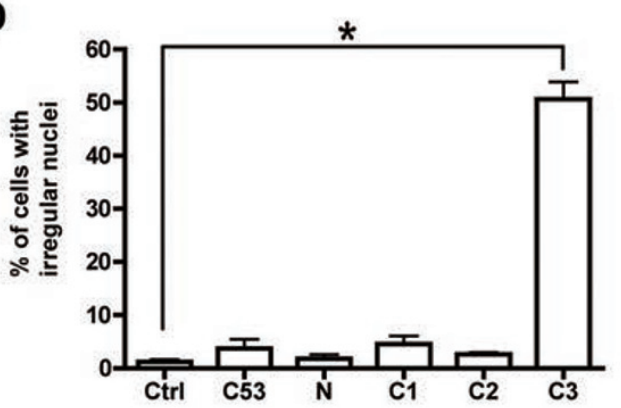

Figure 3 Expression of C53/LZAP-C3 fragment resulted in nuclear irregularity. (A) C53/LZAP-C3 expression resulted in irregular nuclear formation. HeLa cells were transfected with plasmids expressing full-length C53/LZAP, C53/LZAP-N and C53/ LZAP-C3 along with H2B-GFP construct at a ratio of 10:1. Live-cell images were acquired by OpenLab software. (B) Timelapse imaging of control and C3-expressing cells. Time-lapse images of three individual C3-expressing cells were presented. (C) The effect of the C3 fragment was independent of cell cycle progression. Thymidine (TH, 2 mM) and hydroxyurea (HU, 4 $\mathrm{mM}$ ) were immediately added into the medium after transfection to arrest the cell cycle in G1/S phases. Cell cycle arrest was confirmed by flow cytometry (Supplementary information, Figure S2). (D) Nuclear irregularity was C53/LZAP-C3-specific. The result represented three independent experiments (mean $\pm \mathrm{SD}$ ). ${ }^{\star} P<0.01$.

of either MT-destabilizing agent (nocodazole) or actin filament inhibitor (cytochalasin B) on nuclear irregularity induced by $\mathrm{C} 3$ expression. As shown in Figure 5A, a brief treatment by nocodazole significantly inhibited the effect of $\mathrm{C} 3$. In comparison, inhibition of actin filament formation had a minimal effect (Figure 5B), sug- 
A

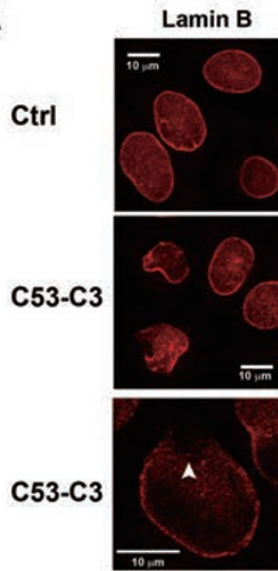

C53-C3

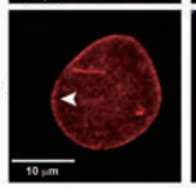

C
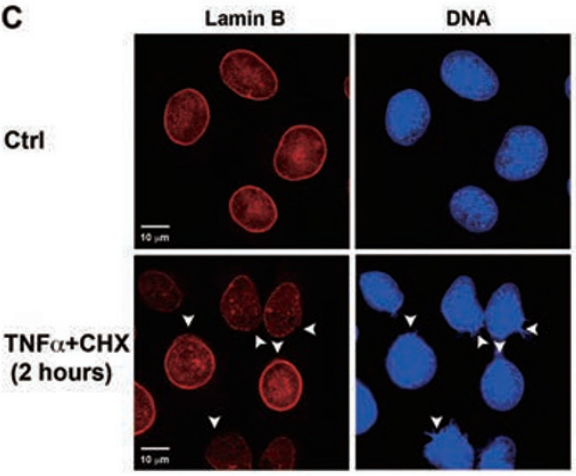

$\mathbf{F}$
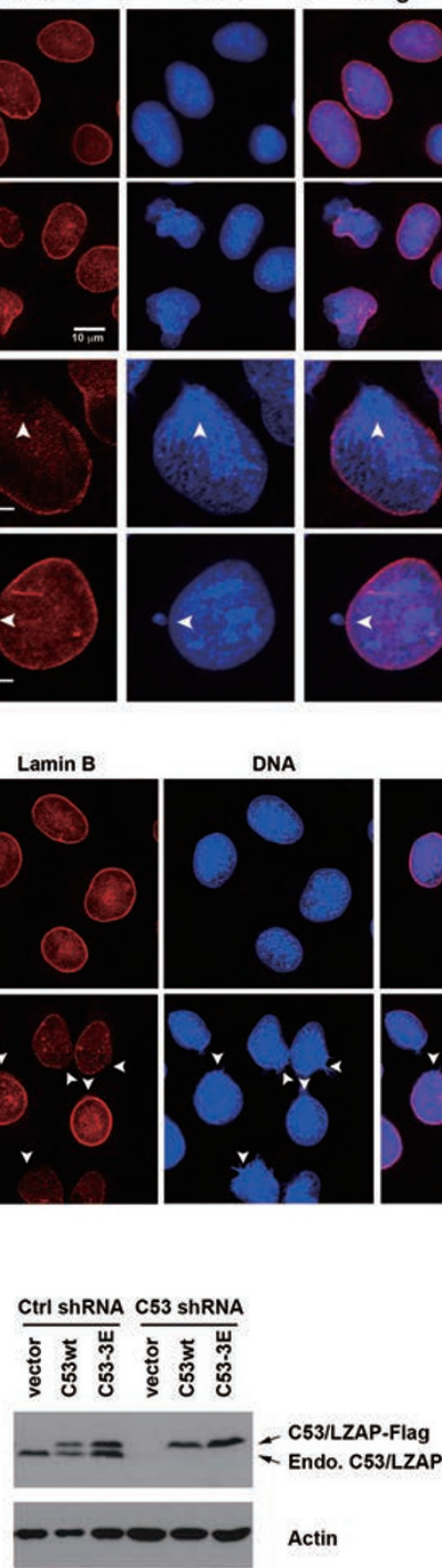

B
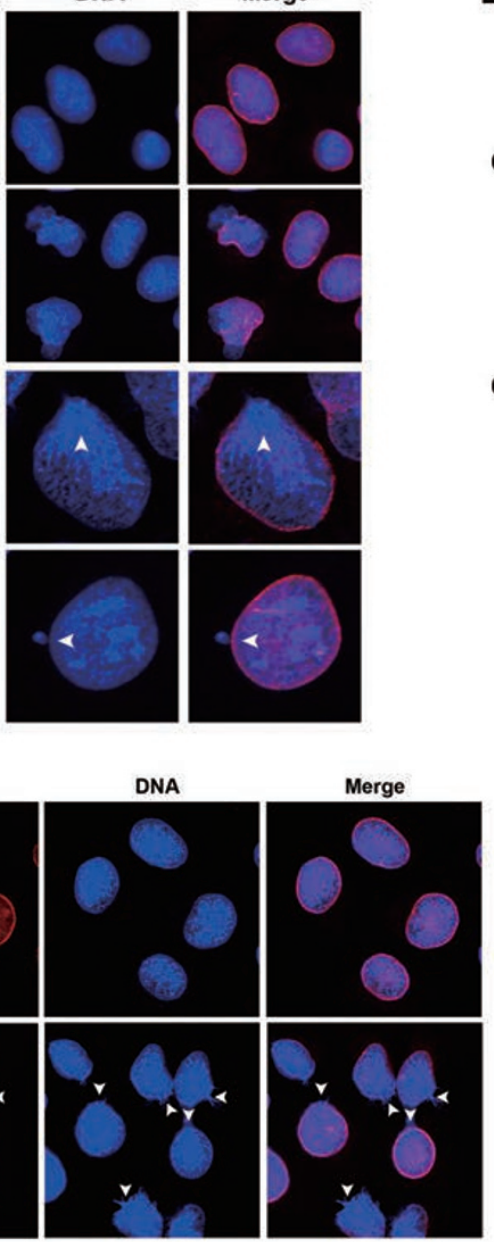

E
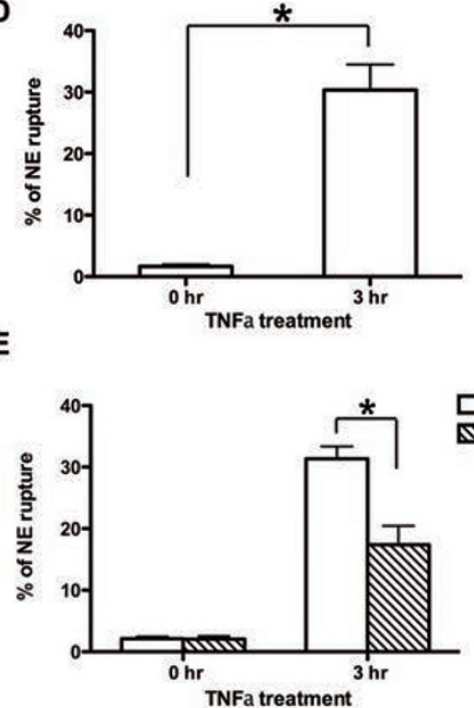

G

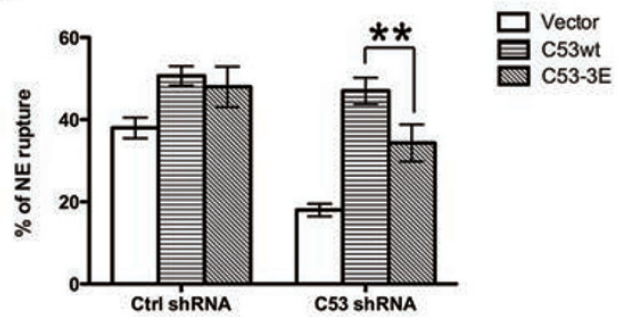

Figure 4 Expression of C53/LZAP caused NE rupture. (A) The C3 fragment induced NE rupture. Integrity of the NE was evaluated by lamin B staining. The sites of NE rupture and disruption of lamin staining were indicated by arrowheads. (B) Partial NE breakdown in the C3-expressing cells examined by electron microscopy. The nucleus was indicated by "N", while the cytoplasm was marked by "C". The region with NE rupture was marked by an arrowhead. (C) Rupture of the NE occurred in the early stage of apoptosis induced by TNF $\alpha$ in HeLa cells. The sites with ruptured NE were marked by arrowheads. (D) The percentage of cells with NE rupture in TNF $\alpha$-induced apoptosis of HeLa cells. The result represented three independent experiments (mean $\pm \mathrm{SD}$ ). ${ }^{*} P<0.01$. (E) The percentage of cells with ruptured NE in C53/LZAP-knockdown cells. The result represented three independent experiments (mean $\pm \mathrm{SD}$ ). ${ }^{*} P<0.01$. (F) Expression of shRNA-resistant wild-type (C53wt) and cleavage-defective mutant (C53/LZAP-3E) in control and C53/LZAP knockdown cells. (G) TNF $\alpha$-induced NE rupture in control or C53/LZAP knockdown cells that expressed either wild-type (C53wt) or mutant (C53/LZAP-3E) C53/LZAP protein. The control or C53 knockdown cells were infected with lentiviruses expressing either C53wt/LZAP or C53/LZAP-3E mutant. After $72 \mathrm{~h}$ post infection, the cells were treated with TNF $\alpha(10 \mathrm{ng} / \mathrm{ml})$ plus $\mathrm{CHX}(10 \mu \mathrm{g} / \mathrm{ml})$ for $3 \mathrm{~h}$, and subsequently fixed and immunostained with lamin B1 antibody. NE rupture was scored in more than 200 cells with RFP marker. The result represented three independent experiments (mean \pm SD). ${ }^{*} P<0.05$. 
gesting that the microtubule plays an important role in C3-induced nuclear irregularity. Immunostaining of the microtubule showed that the microtubule network in C3-expressing cells formed thick bundles around the irregular nuclei (Figure 5C). Electron micrographs further revealed that thick MT bundles formed around ruptured nuclei (marked by arrowheads, Figure 5D), and a portion of the NE (marked by white arrowhead) was attached to the bundled MT (Figure 5D). We also examined whether MT bundling occurred during apoptosis. Excessive MT bundling did occur in the early stage of TNF $\alpha$-induced apoptosis (Figure 5E), and C53/LZAP knockdown reduced the MT bundling and cell death (Figure 5F and $5 \mathrm{G})$. These results suggest that excessive MT bundling is an early event of apoptosis, and this abnormal MT activity induced by C53/LZAP-C3 may contribute to nuclear irregularity and NE rupture.

\section{C53/LZAP indirectly binds to the microtubule}

C53/LZAP has been demonstrated to interact with many proteins, including $\gamma$-tubulin in the nucleoli [13]. Our previous study also showed that a fraction of C53/ LZAP was localized at the centrosome, an organelle that serves as the major cellular MT-organizing center [7]. The effect of C53/LZAP-C3 on MT dynamics raised an intriguing question: is C53/LZAP a bona fide MTbinding protein? As shown in Figure 6A, C53/LZAP was largely distributed in the cytosol, with a pattern that generally followed the MT network, and partially colocalized with the MT in the MT-rich areas such as the peripheries of the nuclei and centrosomes (Figure 6A). To examine whether C53/LZAP binds to the MT, we conducted conventional MT assembly/disassembly assays using mouse brain lysate. A large fraction of cytosolic C53/LZAP was pelleted by $100000 \times g$ centrifugation (comparing lane 2 to lane 3, Figure 6B), indicating that a relatively large amount of C53/LZAP may associate with the light membranes in the brain lysate. Intriguingly, like Tau and p35, two well-known MT-binding proteins, C53/ LZAP in the S100 cytosol apparently cosedimented with the assembled MT (lane 4, Figure 6B). The assembled MT was subject to a second round of disassembly/assembly, and C53/LZAP also cosedimented with re-assembled MT (lane 5, Figure 6B). We also examined whether C53/ LZAP cleavage products bound to the MT. The resulting S100 lysate from HeLa cells treated with TNF $\alpha$ and CHX was subject to in vitro MT assembly assay. As shown in Figure 6C, the cleavage products of C53/LZAP cosendimented with the assembled MT. To further test whether C53/LZAP binds to the MT directly, we performed in vitro MT-binding protein spin-down assay using highly purified tubulins. As illustrated in Figure 6D, purified GST-C53/LZAP did not bind to the assembled MT in vitro. Taken together, our results suggest that C53/ LZAP binds to the MT in an indirect manner.

\section{Discussion}

Apoptosis involves multiple highly coordinated biochemical and cellular events that lead to characteristic morphological changes and ultimately cell death. One of the remarkable events during apoptosis is nuclear fragmentation and condensation. Yet how the apoptotic machinery, including multiple caspases, translocates from the cytoplasm to the nucleus remains less defined. Previous studies have shown that increased leakiness of nuclear pores induced by caspases may be responsible for translocation of active caspases to the nucleus [1]. Here, we show that physical rupture of NE occurs in the early stage of TNF $\alpha$-induced apoptosis. Furthermore, we found that caspase-mediated cleavage of C53/LZAP protein caused abnormal MT bundling and rupture of NE. Our findings provide novel insights into an alternative mechanism for disruption of the nuclear-cytoplasmic barrier during apoptosis.

Caspases play a central role in the initiation and execution of apoptosis. Caspase-mediated cleavage of a large set of specific proteins, including many nuclear targets, is responsible for most of the characteristic apoptotic changes. It has been known that the NE usually breaks down in a caspase-dependent manner, partly due to the cleavage of multiple NE proteins such as lamins [2, $19,20]$. However, most of caspases are activated in the cytoplasm through well-defined molecular mechanisms, and how these active caspases reach their nuclear targets remains less clear. One possible mechanism is that active caspases are transported into the nucleus through nuclear pore complexes. This scenario appears unlikely because nuclear transport is inactivated by caspases [1]. Alternatively, it was reported that leakiness of the NE was increased in a caspase-9-dependent manner, possibly due to the increase of the diffusion limit of nuclear pores [1]. Cleavage of the nuclear pore components such as Nup153 may contribute to the increase of diffusion limit [2]. In this study, we observed that NE became physically ruptured in the early stage of $\mathrm{TNF} \alpha$-induced apoptosis (Figure 4), which may render the NE permeable for translocation of active caspases and facilitate destruction of the nucleus.

What causes rupture of the NE? Our study strongly suggests that C53/LZAP protein is involved in this process. C53/LZAP is a highly conserved protein that plays important roles in multiple signaling pathways $[5,7]$. It has also been implicated in tumorigenesis and metastasis 
A
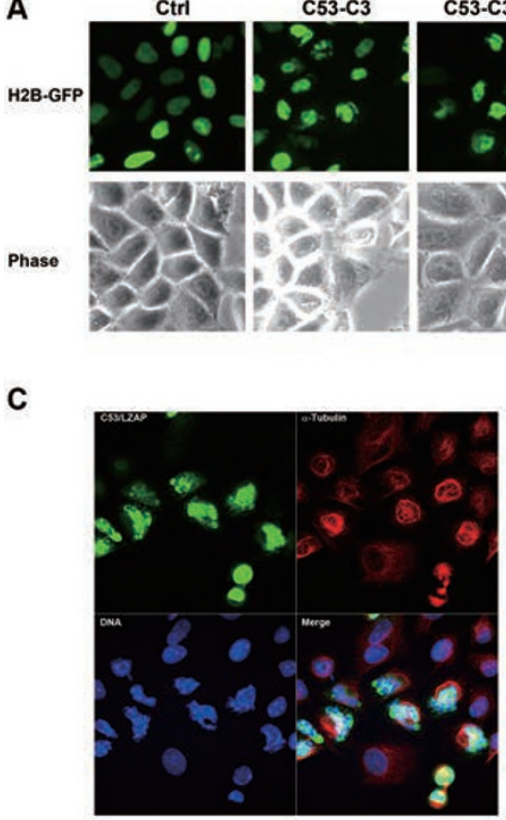

C53-C3+TH $\mathrm{C} 53-\mathrm{C} 3+\mathrm{TH}+\mathrm{NoCO}$

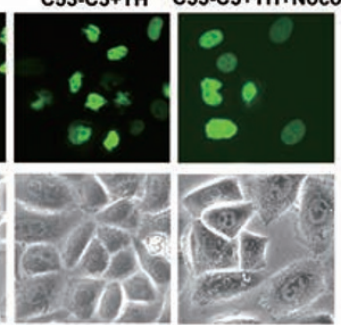

B

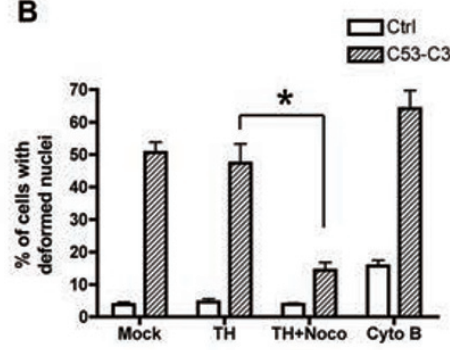

\section{C}

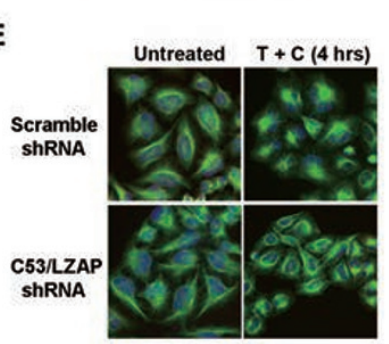

F

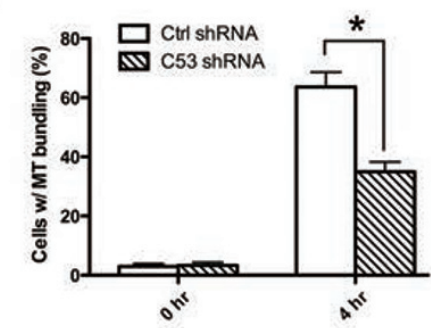

D

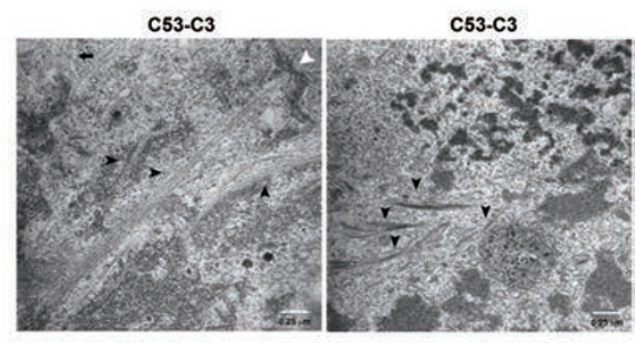

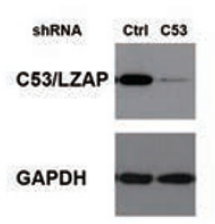

G

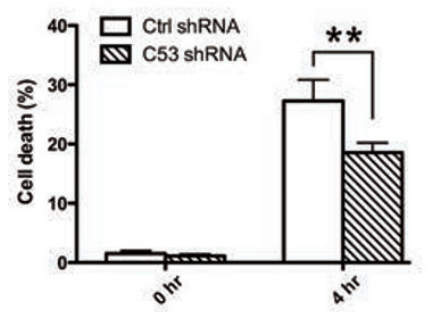

Figure 5 C53/LZAP-C3-induced nuclear irregularity was MT-dependent. (A) Nuclear irregularity induced by the C3 fragment was inhibited by MT-disrupting agent nocodazole. To exclude the effect of nocodazole on the cell cycle progression, thymidine (2 mM) was added to arrest the cell cycle in the G1/S phase. HeLa cells were transfected with C3 plasmid along with H2B-GFP. At $4 \mathrm{~h}$ post transfection, thymidine $(2 \mathrm{mM})$ and nocodazole $(100 \mathrm{ng} / \mathrm{ml})$ were added to the medium. Live-cell images were acquired after $12 \mathrm{~h}$ incubation. (B) The effect of C3 was independent of the actin filament. Cytochalasin B (1 $\mu \mathrm{M})$ was added to the transfected cells at $4 \mathrm{~h}$ after transfection. The result represented three independent experiments (mean \pm SD). ${ }^{*} P<0.01$. (C) Abnormal MT bundles appeared around irregular nuclei in C53/LZAP-C3-expressing cells. The cells with C3 expression were indicated by C53/LZAP staining. (D) Thick MT bundles were present in C3-expressing cells. Thick MT bundles were marked by arrowheads, while regular MT was indicated by an arrow at the upper left corner. A piece of the NE attached to the bundled MT was marked by a white arrowhead. (E) Excessive MT bundling occurred in TNF $\alpha$-induced apoptosis. HeLa cells (control and C53 knockdown) were treated with TNF $\alpha$ (10 ng/ml) and CHX (10 $\mu \mathrm{g} / \mathrm{ml})$ for $4 \mathrm{~h}$. Cells were fixed with 4\% PFA and immunostained with $\alpha$-tubulin antibody. C53 knockdown was confirmed by western blotting. (F) Quantification of the cells with MT bundles induced by TNF $\alpha$ treatment. Control and C53/LZAP-knockdown cells were treated with TNF $\alpha(10 \mathrm{ng} / \mathrm{ml})$ and $\mathrm{CHX}(10 \mu \mathrm{g} / \mathrm{ml})$ for $4 \mathrm{~h}$. The result represented three independent experiments $(\mathrm{mean} \pm \mathrm{SD}) .{ }^{*} P<0.01$. (G) Cell death of control and C53-knockdown cells induced by TNF $\alpha$ treatment. Control and C53-knockdown cells were treated with TNF $\alpha(10 \mathrm{ng} / \mathrm{ml})$ and $\mathrm{CHX}(10 \mu \mathrm{g} / \mathrm{ml})$ for $4 \mathrm{~h}$. Cell death percentage was scored by double staining of calcein-AM and PI (Sigma). The results represented three independent experiments (mean $\pm \mathrm{SD}$ ). ${ }^{* \star} P<0.05$. 
A
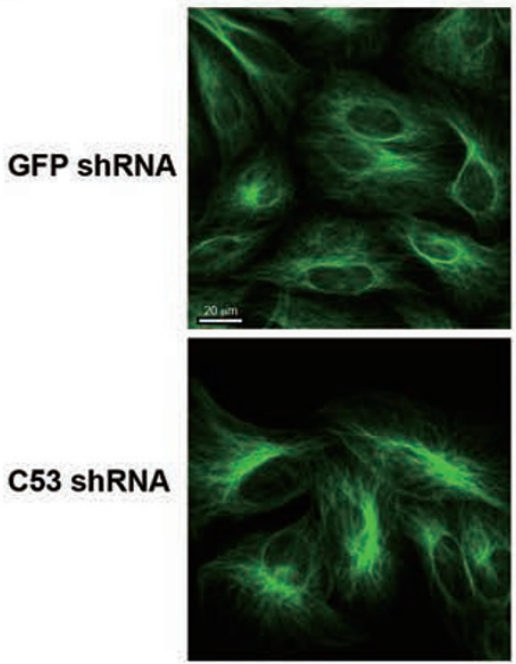

B

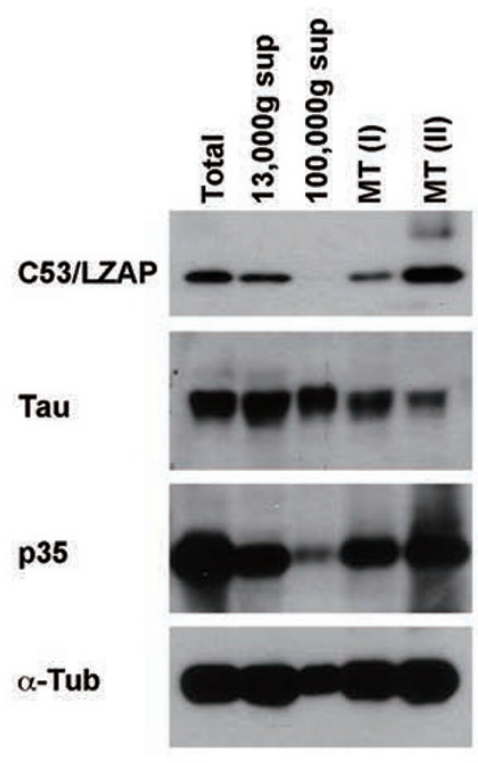

C53 ShRNA
C53/LZAP
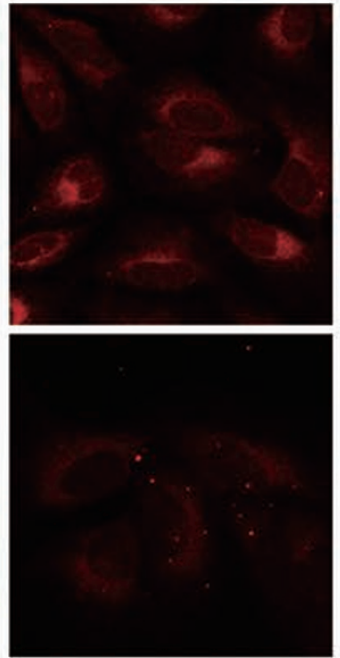

C
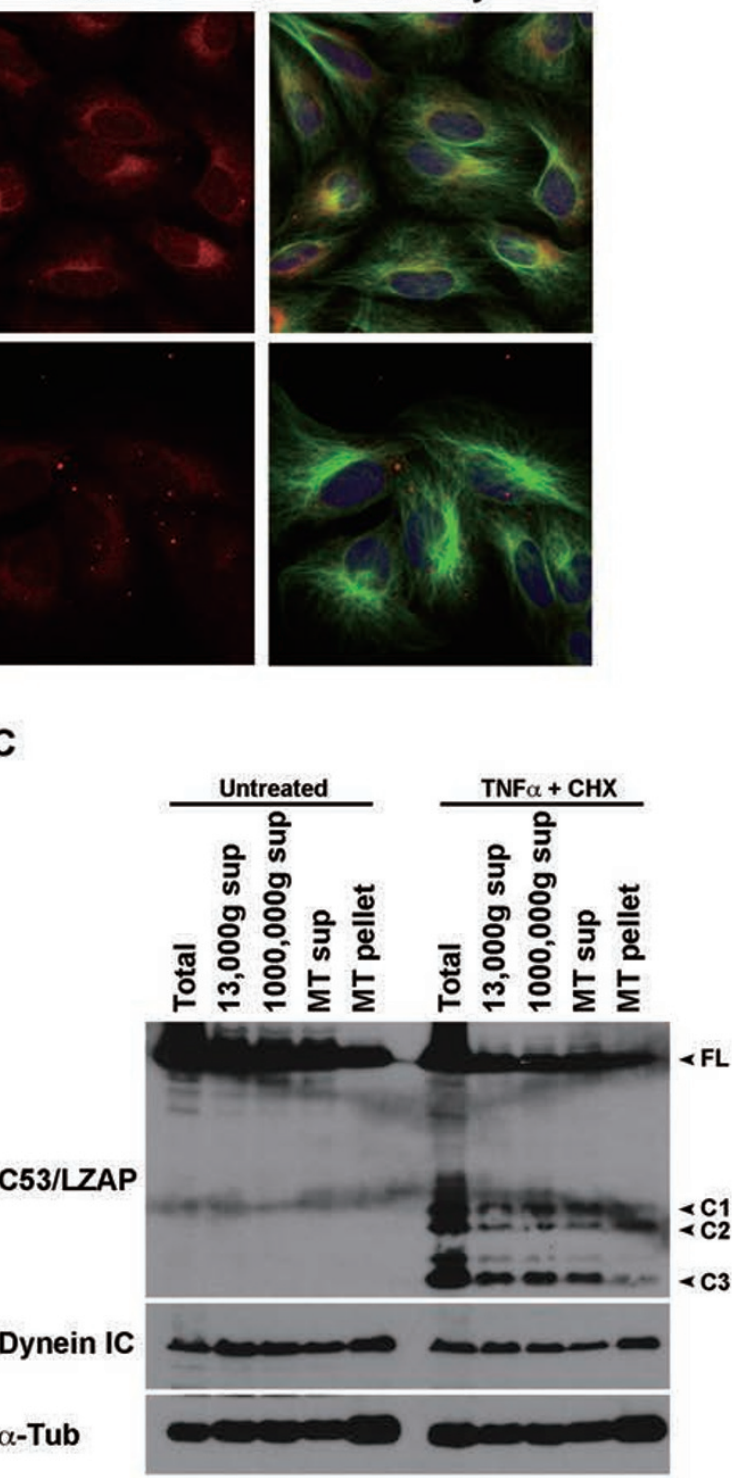

D

$\begin{array}{lllllllllll}\mathrm{MT} & + & + & - & - & + & + & - & - & + & + \\ \mathrm{MAPF} & - & - & + & + & + & + & - & - & - & - \\ \mathrm{BSA} & \dot{-} & - & - & - & - & - & + & + & + & + \\ & \mathbf{P} & \mathbf{S} & \mathbf{P} & \mathbf{S} & \mathbf{P} & \mathbf{S} & \mathbf{P} & \mathbf{S} & \mathbf{P} & \mathbf{s}\end{array}$
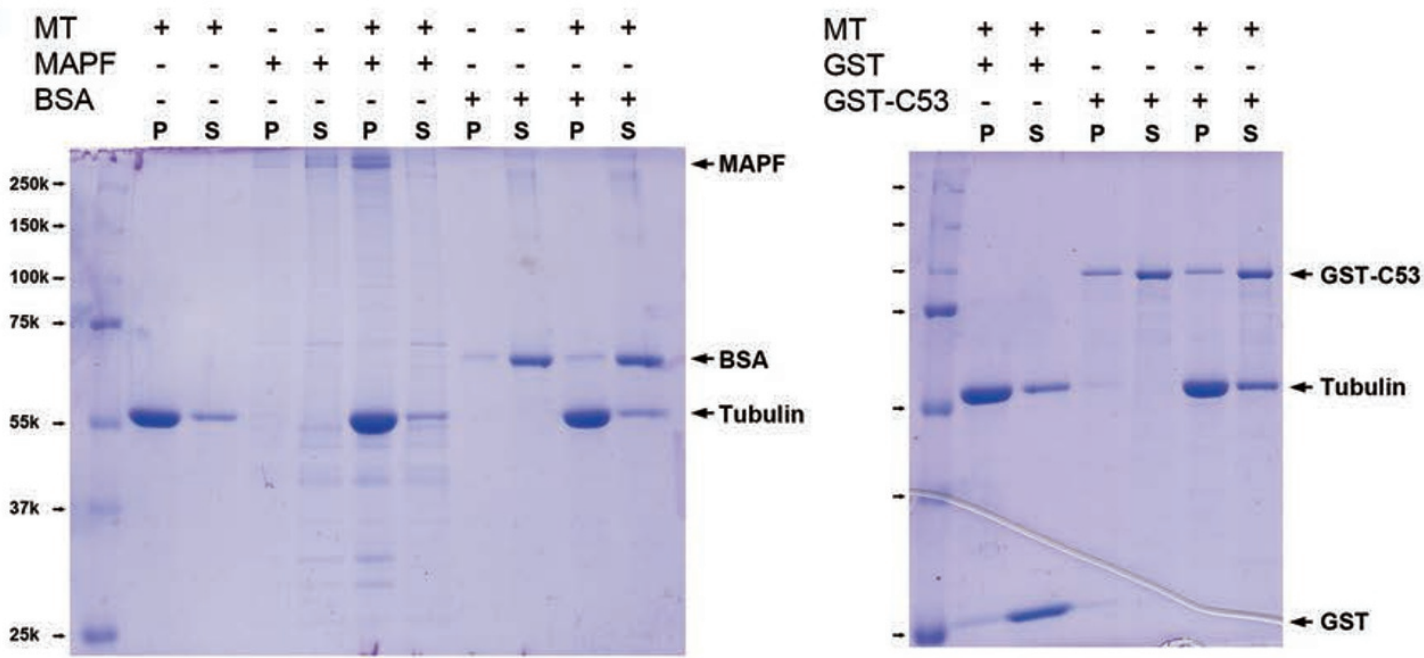
even though the conclusion of those reports appeared to differ [5, 9-11]. We originally isolated C53/LZAP as a caspase substrate from a large-scale screening of caspase substrates using the strategy of in vitro expression cloning (Figure 1). Mutagenesis study identified three caspase-3-cleavage sites, DAID ${ }^{268}$, EGTD ${ }^{282}$ and DGID ${ }^{311}$, all of which are located in the middle of the protein and match well with the consensus caspase- 3 cleavage sequence DXXD (Figure 2). Multiple alignment of C53/ LZAP orthologues from various species (human, mouse, Drosophila and C. elegans) suggests that both N- and $\mathrm{C}$-terminal portions of the protein are highly conserved, while the middle part is less conserved. However, the D268- and D311-cleavage sites are conserved among the species, indicating that caspase-mediated cleavage may have a conserved functional consequence. Interestingly, there are three highly conserved IDWG repeats in the middle of the protein overlapping some caspase-cleavage sites, and their function remains to be elucidated.

We found that expression of one of the C53/LZAP cleavage products, C3, caused significant nuclear irregularity that was independent of cell cycle progression, even though expression of full-length C53/LZAP or N-terminal cleavage products induced less severe irregularity (Figure 3). Further examination of the cells with irregular nuclei revealed that genomic DNA was "leaked" out from disrupted NE, and expression of C53C3 led to partial rupture or complete breakdown of the NE (Figure 4). Knockdown of C53/LZAP decreased the NE rupture in TNF $\alpha$-induced apoptosis (Figure 4), suggesting that C53/LZAP is indeed important for disruption of the nuclear-cytoplasmic barrier during apoptosis. Additionally, C53/LZAP may also affect apoptotic signaling through other mechanisms such as its involvement in NF- $\mathrm{KB}$ signaling and DNA damage response $[5,6]$. Interestingly, caspases also exert non-apoptotic functions under various physiological conditions. For example, it was reported that small transient NE disruption involving host caspase-3 plays an important role in the parvovi- rus replication cycle [21]. It would be of interest to test whether caspase-mediated cleavage of C53/LZAP is also involved in this type of viral replication cycle.

How does C53/LZAP-C3 disrupt the NE? The NE is an extension of the endomembrane system that interacts with the cytoskeleton, especially the microtubule network. The nucleus also closely interacts with the microtubule through the so-called LINC (linker of the nucleoskeleton and cytoskeleton) complex that contains Nesprins and SUN proteins [22]. The NE is a highly dynamic structure that reversibly disassembles and reforms during cell cycle. One well-studied system of the NE dynamics is the NE breakdown (NEBD) during mitosis. The prevailing model for the triggering of NEBD is phosphorylation of lamins and other NE components by active cyclin-dependent kinase $1(\mathrm{Cdk} 1)$, resulting in lamina dissociation and disassembly of the NE [23]. However, recent studies by Salina et al. [24] and Beaudouin et al. [25] suggest an alternative mechanism by which NEBD is triggered by dynein-mediated forces that tears the NE apart, thereby facilitating NE disassembly. We found that the $\mathrm{C} 3$ fragment induced formation of abnormal MT bundles around the nuclei, and the NE appeared to be physically torn apart by this abnormal MT activity (Figure 5). Our finding that the MT-destabilizing agent nocodazole antagonized the effect of $\mathrm{C} 3$, further supports the role of MT in C3-induced NE rupture. Although there may be difference in the cellular context of NEBD in mitosis and C3-induced NE rupture, it is very likely that dynein or other MT-motors may play a similar role in C3-induced NE rupture. Expression of the C3 fragment may aberrantly activate the MT motor(s) that leads to tearing-apart of the NE. Interestingly, the cellular distribution of C53/LZAP appears to generally follow the MT network and partially colocalizes with the MT (Figure 6). In vitro $\mathrm{MT}$ assembly assay clearly demonstrated that C53/LZAP was associated with the assembled MT but did not bind MT directly (Figure 6), indicating that C53/ LZAP may bind to the MT through other MT-binding

Figure 6 C53/LZAP bound to the microtubule indirectly. (A) C53/LZAP was partially colocalized with the MT. Control and C53/LZAP-knockdown U2OS cells were stained with C53/LZAP (red) and $\alpha$-tubulin (green) antibodies. The specificity of C53/ LZAP antibody was confirmed by dimmed staining in the knock-down cells as well as by the previous report [7]. (B) MT assembly/disassembly assay using mouse brain lysate. $13000 \mathrm{~g}$ sup was the supernatant fraction after $13000 \times \mathrm{g}$ centrifuga-

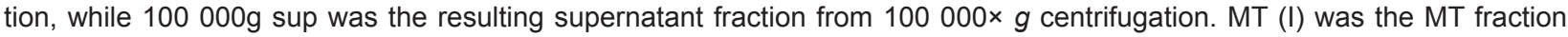
from the first assembly cycle, while MT (II) was the MT fraction from the second assembly/disassembly cycle. Tau and p35 are the known MT-associated proteins. (C) MT assembly assay using HeLa cell lysate. HeLa cells $\left(1 \times 10^{7}\right)$ were treated with $\mathrm{TNF} \alpha(10 \mathrm{ng} / \mathrm{ml})$ and $\mathrm{CHX}(10 \mu \mathrm{g} / \mathrm{ml})$ for $16 \mathrm{~h}$. In vitro MT assembly assay was conducted with either untreated or treated

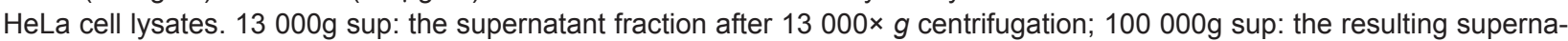
tant fraction from $100000 \times \mathrm{g}$ centrifugation; MT sup: the supernatant from the centrifugation after MT assembly; MT pellet: the assembled MT pellet. (D) In vitro MT-binding assay. The assay was conducted with the MT-binding protein spin-down assay kit. Both positive (MAPF, > $250 \mathrm{kD}$ ) and negative (BSA, $66 \mathrm{kD}$ ) controls were provided by the kit. 
proteins. Such mediators may include p35 [26] and other potential C53/LZAP-interacting protein such as Disrupted-in-Schizophrenia 1 (DISC1) protein, which is also known to bind the microtubule [27, 28]. Meanwhile, a relatively large fraction of cytoplasmic C53/LZAP is associated with light membranes, such as the ER (Figure $6 \mathrm{~B}$ and [12]), probably through its interaction with the ER protein RCAD (also known as Ufl1, NLBP and MAXER) [12, 15-17]. Therefore, C53/LZAP appears to serve as an important linker between the microtubule network and the endomembrane system. The presence of the C3 fragment may disrupt this important link and lead to rupture of the NE. Further study will be conducted to elucidate the molecular mechanism by which C53/LZAP regulates the microtubule dynamics and its role in animal development and human diseases.

\section{Materials and Methods}

\section{Tissue culture cells and chemical reagents}

U2OS osteosarcoma cells (ATCC) were grown in McCoy's 5A medium supplemented with $10 \%$ fetal bovine serum (FBS), and HeLa and HCT116 cells were cultured in Dulbecco's modified Eagle's medium (DMEM) supplemented with $10 \%$ FBS and antibiotics. Chemical reagents were purchased from Sigma.

In vitro expression cloning, and construction of C53/LZAP expression and ShRNA vectors

In vitro expression cloning was originally conducted in $\mathrm{Dr}$ Junying Yuan's laboratory (Harvard Medical School, USA) using mouse spleenocyte small pools of cDNA library [29]. Human fulllength C53/LZAP cDNA and the cDNAs for its truncated fragments were described previously by Jiang et al. [7] and Wu et al. [12]. Site-specific mutagenesis was performed using QuikChange Site-directed Mutagenesis kit (Stratagene).

Lentiviral vectors expressing scrambled shRNA or C53/LZAP shRNA (5'-GCAGGAGATTATAGCTCTGTA-3') were constructed using pLKO.1 vector. Lentiviruses were prepared using 293FT packaging cell line according to the manufacturer's instruction (Invitrogen).

For expression of shRNA-resistant wild-type and mutant FlagC53/LZAP proteins, five sense point mutations have been introduced into the region of C53/LZAP cDNA corresponding to its shRNA target sequence using standard two-step PCR reactions without changing its protein sequence. Specifically, two PCR reactions were carried out using two sets of primers: for N-terminal fragment, 5'-AAGCGGCCGCATGGAGGACCATCAGCACGTG-3' (forward primer) and 5'-GGTGTTGTCCTTCTCATATAAAGCGATGATTTCCTGCCAATCCTT-3' (mutated nucleotides are bolded); for C-terminal fragment, 5'-AAGGATTGGCAGGAAATCATCGCTTTATATGAGAAGGACAACACC-3' (mutated nucleotides are bolded) and 5'-AAGTTAACCTACTTGTCATCGTCGTCCTTGTAATCCAG-3' (reverse primer, containing Flag-tag). The full-length cDNA was amplified with forward and reverse primers using the two fragments as the template. The PCR product was further subcloned into the NotI and $H p a \mathrm{I}$ sites of pHIV-dTomato vector (Addgene no. 21374). Lentiviruses express- ing wild-type and mutant C53/LZAP were prepared as described above.

\section{Cell-transient transfection and C53/LZAP knockdown by shRNA}

For expression of C53/LZAP and its derivatives, the plasmids expressing C53/LZAP and its truncated fragments were transiently transfected into HeLa cells using Lipofectamine 2000 following the standard procedure (Invitrogen). Alternatively, HeLa cells were infected with the lentiviruses expressing C53/LZAP and its mutants.

For C53/LZAP knockdown, cells were infected with lentiviruses expressing either scramble or C53 shRNAs. At $24 \mathrm{~h}$ post infection, cells were selected with puromycin $(1.5 \mu \mathrm{g} / \mathrm{ml})$ for extra 3 days. C53/LZAP knockdown was confirmed by immunoblotting.

\section{Antibodies, immunoblotting, immunofluorescence staining and EM microscopy}

C53/LZAP polyclonal rat antibody was described previously in Jiang et al. [7] and Wu et al. [12]. Two rabbit polyclonal antibodies of human C53/LZAP were also generated against two peptides (residues 242-256, KRGNSTVYEWRTGTE, and residues 491506, SKRYSGRPVNLMGTSL), respectively. Polysera were further purified using affinity column crosslinked with respective peptides (Pierce).

Immunoblotting and immunofluorescence staining were performed as described by Wu et al. [12]. Confocal images were acquired using Zeiss 510 META confocal microscope, whereas epifluorescence images were obtained using Leica DMR-HC inverted microscope with OpenLab software and Zeiss Observer D1 with AxioVision 4.8 software. Time-lapse images were acquired with OpenLab software.

The following antibodies at the indicated dilutions were used for immunoblotting: C53 polyclonal rat antibody (affinity purified, 1:1 000 dilution), caspase-7 and -8 (gifts from Dr Junying Yuan, Harvard Medical School, USA, 1:10), caspase-3 and -9 (Cell Signaling, 1:1 000), p35 (Santa Cruz, 1:1 000), Tau (Santa Cruz, 1:1 000), $\alpha$-tubulin (Sigma, 1:10 000). $\beta$-actin (Sigma, 1:10 $000)$. The following antibodies at the indicated dilutions were used for immunofluorescence staining: C53 (1:50), $\alpha$-tubulin (Sigma, 1:2 000). All affinity-purified and species-specific fluorophoreconjugated secondary antibodies were obtained from Jackson ImmunoResearch, and used at dilutions between 1:400 and 1:800.

EM microscopy was conducted as described by Wu et al. [12]. Briefly, cells were fixed with $2.5 \%$ glutaraldehyde in $0.1 \mathrm{M}$ sodium phosphate buffer, $\mathrm{pH} 7.4$ at $4{ }^{\circ} \mathrm{C}$ for $30 \mathrm{~min}$. Cells were then scraped from tissue culture dish and harvested by centrifugation at $3000 \mathrm{rpm}$ for $10 \mathrm{~min}$. The cell pellet was further fixed in $2.5 \%$ glutaraldehyde for $2 \mathrm{~h}$ and post-fixed with $1 \%$ osmium tetroxide for $2 \mathrm{~h}$ at $4{ }^{\circ} \mathrm{C}$. The cell pellet was dehydrated in an ethanol gradient (50\%-100\% for 10 min each) and embedded in Epon 812 at 60 ${ }^{\circ} \mathrm{C}$ for 2 days. Ultrathin sections were stained with uranyl acetate and lead citrate, and pictures were taken by a Zeiss 900 electron microscope.

\section{In vitro caspase cleavage assay}

In vitro transcription and translation of C53/LZAP were performed as described previously [30]. ${ }^{35} \mathrm{~S}$-labeled proteins were incubated with bacterial lysates containing active caspases, and the 
cleavage was evaluated by SDS-PAGE and autoradiography.

\section{Cell death assay}

Cell death percentage was evaluated by Double-staining kit (Sigma). Calcein-AM and propidium iodide (PI) can stain viable and dead cells, respectively. Cells were treated with apoptosisinducing agents, and then stained with calcein-AM $(0.5 \mu \mathrm{M})$ and PI $(1 \mu \mathrm{M})$ for 15-30 min, followed by fluorescence microscopy. Cell death percentage was scored by counting more than 200 of calcein-AM-positive (viable) and PI-positive (dead) cells.

MT isolation, assembly/disassembly, and in vitro MT-binding protein spin-down assay

Mouse brain microtubules were isolated by temperature-dependent assembly/disassembly experiments according to the report by Hou et al. [26]. Briefly, mouse brain was homogenized on ice in 2-folds (v/w) of homogenization buffer (PEM buffer plus $100 \mathrm{mM}$ $\mathrm{NaCl}, 0.1 \%$ triton X-100, $1 \mathrm{mM}$ DTT, $10 \mathrm{mM} \mathrm{NaF}, 0.1 \mathrm{mM} \mathrm{Na}-$ ${ }_{3} \mathrm{VO}_{4}, 10 \mathrm{mM} \beta$-glycerophosphate and the protease inhibitor cocktail (Sigma)). The homogenate was cleared by centrifugation at 4 ${ }^{\circ} \mathrm{C}$ first at $20000 \times g$ for $45 \mathrm{~min}$ and then at $100000 \times g$ for $45 \mathrm{~min}$. MT assembly was initiated in the extract by the addition of $30 \%$ (v/ v) glycerol and $1 \mathrm{mM} \mathrm{GTP}$ and was conducted at $35^{\circ} \mathrm{C}$ for $45 \mathrm{~min}$. Microtubules that were centrifuged down at $35^{\circ} \mathrm{C}(100000 \times \mathrm{g}, 45$ $\mathrm{min}$ ), were designated as MT (I) fraction (Figure 6B). The pelleted microtubules were resuspended by homogenization in the ice-cold homogenization buffer and were allowed to disassemble on ice for $45 \mathrm{~min}$. After centrifugation at $4{ }^{\circ} \mathrm{C}(100000 \times g, 45 \mathrm{~min})$ to pellet undisrupted microtubules, the resulting supernatant was used for another cycle of microtubule assembly. The resulting microtubules were designated as MT (II) fraction. Aliquots of fractions were lysed in protein buffer and subjected to SDS-PAGE analyses. Similar assays were also performed using HeLa cell lysates.

In vitro MT-binding protein spin-down assay was performed using the kit from Cytoskeleton, Inc. according to the manufacturer's instruction. GST and GST-C53 proteins were dialyzed in PEM buffer ( $80 \mathrm{mM}$ PIPES pH 7.0, $2 \mathrm{mM} \mathrm{MgCl}$ and $0.5 \mathrm{mM}$ EGTA) prior to the assay.

\section{Acknowledgments}

We thank Dr Hongtao Yu (UT Southwestern Medical Center, USA) for H2B-GFP construct and Dr Yi Tang (Children's Memorial Hospital, Northwestern University, USA) for excellent technical support on electron microscopy. Dr Isabelle De Plaen and her colleagues (Children's Memorial Hospital, Northwestern University, USA) provided mouse-brain tissues. The original screening of caspase substrates was conducted in Dr Junying Yuan's laboratory (Harvard Medical School, USA). The project was supported by NIH grant R01 (GM081776) to H Li.

\section{References}

1 Faleiro L, Lazebnik Y. Caspases disrupt the nuclear-cytoplasmic barrier. J Cell Biol 2000; 151:951-959.

2 Buendia B, Santa-Maria A, Courvalin JC. Caspase-dependent proteolysis of integral and peripheral proteins of nuclear membranes and nuclear pore complex proteins during apoptosis. J Cell Sci 1999; 112: 1743-1753.
3 Ching YP, Qi Z, Wang JH. Cloning of three novel neuronal Cdk5 activator binding proteins. Gene 2000; 242:285-294.

4 Wang J, He X, Luo Y, Yarbrough WG. A novel ARF-binding protein (LZAP) alters ARF regulation of HDM2. Biochem $J$ 2006; 393:489-501.

5 Wang J, An H, Mayo MW, Baldwin AS, Yarbrough WG. LZAP, a putative tumor suppressor, selectively inhibits NFkappaB. Cancer Cell 2007; 12:239-251.

6 Jiang $\mathrm{H}$, Luo S, Li H. Cdk5 activator-binding protein C53 regulates apoptosis induced by genotoxic stress via modulating the G2/M DNA damage checkpoint. J Biol Chem 2005; 280:20651-20659.

7 Jiang H, Wu J, He C, Yang W, Li H. Tumor suppressor protein C53 antagonizes checkpoint kinases to promote cyclindependent kinase 1 activation. Cell Res 2009; 19:458-468.

8 Liu D, Wang WD, Melville DB, et al. Tumor suppressor Lzap regulates cell cycle progression, doming, and zebrafish epiboly. Dev Dyn 2011; 240:1613-1625.

9 Mak GW, Chan MM, Leong VY, et al. Overexpression of a novel activator of PAK4, the CDK5 kinase-associated protein CDK5RAP3, promotes hepatocellular carcinoma metastasis. Cancer Res 2011; 71:2949-2958.

10 Zhao JJ, Pan K, Li JJ, et al. Identification of LZAP as a new candidate tumor suppressor in hepatocellular carcinoma. PLoS One 2011; 6:e26608.

11 Chen J, Shi Y, Li Z, et al. A functional variant of IC53 correlates with the late onset of colorectal cancer. Mol Med 2011; 17:607-618.

12 Wu J, Lei G, Mei M, Tang Y, Li H. A novel C53/LZAP-interacting protein regulates stability of C53/LZAP and DDRGK domain-containing Protein 1 (DDRGK1) and modulates NFkappaB signaling. J Biol Chem 2010; 285:15126-15136.

13 Horejsi B, Vinopal S, Sladkova V, et al. Nuclear $\gamma$-tubulin associates with nucleoli and interacts with tumor suppressor protein C53. J Cell Physiol 2012; 227:367-382.

14 An H, Lu X, Liu D, Yarbrough WG. LZAP inhibits p38 MAPK (p38) phosphorylation and activity by facilitating p38 association with the wild-type p53 induced phosphatase 1 (WIP1). PLoS One 2011; 6: e16427.

15 Tatsumi K, Sou YS, Tada N, et al. A novel type of E3 ligase for the Ufm1 conjugation system. J Biol Chem 2010; 285:5417-5427.

16 Kwon J, Cho HJ, Han SH, No JG, Kwon JY, Kim H. A novel LZAP-binding protein, NLBP, inhibits cell invasion. $J$ Biol Chem 2010; 285:12232-12240.

17 Shiwaku H, Yoshimura N, Tamura T, et al. Suppression of the novel ER protein Maxer by mutant ataxin-1 in Bergman glia contributes to non-cell-autonomous toxicity. EMBO J 2010; 29:2446-2460.

18 King RW, Lustig KD, Stukenberg PT, McGarry TJ, Kirschner MW. Expression cloning in the test tube. Science 1997; 277:973-974.

19 Takahashi A, Alnemri ES, Lazebnik YA, et al. Cleavage of lamin A by Mch2 alpha but not CPP32: multiple interleukin 1 beta-converting enzyme-related proteases with distinct substrate recognition properties are active in apoptosis. Proc Natl Acad Sci USA 1996; 93:8395-8400.

20 Orth K, Chinnaiyan AM, Garg M, Froelich CJ, Dixit VM. The CED-3/ICE-like protease Mch2 is activated during apoptosis 
and cleaves the death substrate lamin A. J Biol Chem 1996; 271:16443-16446.

21 Cohen S, Marr AK, Garcin P, Pante N. Nuclear envelope disruption involving host caspases plays a role in the parvovirus replication cycle. $J$ Virol 2011; 85:4863-4874.

22 Mellad JA, Warren DT, Shanahan CM. Nesprins LINC the nucleus and cytoskeleton. Curr Opin Cell Biol 2011; 23:4754.

23 Marshall IC, Wilson KL. Nuclear envelope assembly after mitosis. Trends Cell Biol 1997; 7:69-74.

24 Salina D, Bodoor K, Eckley DM, Schroer TA, Rattner JB, Burke B. Cytoplasmic dynein as a facilitator of nuclear envelope breakdown. Cell 2002; 108:97-107.

25 Beaudouin J, Gerlich D, Daigle N, Eils R, Ellenberg J. Nuclear envelope breakdown proceeds by microtubule-induced tearing of the lamina. Cell 2002; 108:83-96.
26 Hou Z, Li Q, He L, et al. Microtubule association of the neuronal p35 activator of Cdk5. J Biol Chem 2007; 282:1866618670.

27 Ewing RM, Chu P, Elisma F, et al. Large-scale mapping of human protein-protein interactions by mass spectrometry. Mol Syst Biol 2007; 3:89.

28 Morris JA, Kandpal G, Ma L, Austin CP. DISC1 (DisruptedIn-Schizophrenia 1) is a centrosome-associated protein that interacts with MAP1A, MIPT3, ATF4/5 and NUDEL: regulation and loss of interaction with mutation. Hum Mol Genet 2003; 12:1591-1608.

29 Li H, Zhu H, Xu CJ, Yuan J. Cleavage of BID by caspase 8 mediates the mitochondrial damage in the Fas pathway of apoptosis. Cell 1998; 94:491-501.

30 Li H, Bergeron L, Cryns V, et al. Activation of caspase-2 in apoptosis. J Biol Chem 1997; 272:21010-21017.

(Supplementary information is linked to the online version of the paper on the Cell Research website.) 